\title{
Estimation of carcass composition using rib dissection of calf-fed Holstein steers supplemented zilpaterol hydrochloride
}

\author{
T. J. McEvers, * N. D. May,* J. A. Reed,* L. J. Walter,* J. P. Hutcheson, ${ }^{\dagger}$ and T. E. Lawrence*1 \\ * Beef Carcass Research Center, West Texas A\&M University, Canyon, TX 79016; and †Merck Animal Health, \\ Summit, NJ 07901
}

\begin{abstract}
A serial harvest was conducted every $28 \mathrm{~d}$ from 254 to $534 \mathrm{~d}$ on feed (DOF) to quantify changes in growth and composition of calf-fed Holstein steers $(n=115$, initial body weight $(\mathrm{BW})=449.2 \pm 19.9 \mathrm{~kg})$. One-half were supplemented with the $\beta-2$ adrenergic agonist zilpaterol hydrochloride (ZH; $8.33 \mathrm{mg} / \mathrm{kg} 100 \%$ dry matter (DM) basis) during the final $20 \mathrm{~d}$ followed by a 3-d withdrawal prior to harvest; the remainder was fed a non-ZH control (CON) ration. Five steers were randomly selected and harvested after 226 DOF which served as a reference point for modeling purposes. Fabricated carcass soft tissue was ground, mixed, and subsampled for proximate analysis. Moreover, following the traditional method of rib dissection which includes the 9th, 10th, and 11 th rib contained within the IMPS 103 primal, the relationship of carcass chemical composition to 9-10-11 rib composition was evaluated. Carcasses in this investigation had more $(P<0.01)$ separable lean, fat, ash, and moisture concomitant with less bone and ether extract than rib dissections. However, protein levels were similar $(P=0.27)$
\end{abstract}

between carcasses and rib dissections. Using regression procedures, models were constructed to describe the relationship of rib dissection (RD) composition including separable lean (RDSL), separable fat (RDSF), separable bone (RDSB), ether extract (RDEE), protein (RDP), moisture (RDM), and ash (RDA) with carcass composition. Carcass lean $(\mathbf{C L})$, carcass fat $(\mathbf{C F})$, and carcass bone $(\mathbf{C B})$ were correlated $(P<0.01)$ with RDSL, RDSF, and RDSB with simple $r$ values of $0.41,0.71$, and 0.50 , respectively. Chemical composition of the rib and carcass, carcass ether extract $(\mathbf{C E E})$, carcass protein $(\mathbf{C P})$, carcass moisture $(\mathbf{C M})$, and carcass ash $(\mathbf{C A})$ were correlated $(P \leq 0.01)$ with simple $r$ values of 0.75 , $0.31,0.66$, and 0.37 , respectively. Equations to predict carcass fatness from rib dissection variables and $\mathrm{ZH}$ supplementation status were only able to account for 50 and $56 \%$, of the variability of $\mathrm{CF}$ and CEE, respectively. Overall, the relationships quantified and equations developed in this investigation do not support use of 9/10/11 rib dissection for estimation of carcass composition of calf-fed Holstein steers.

Key words: beef, composition, Holstein, prediction, zilpaterol

(C) The Author(s) 2018. Published by Oxford University Press on behalf of American Society of Animal Science. This is an Open Access article distributed under the terms of the Creative Commons Attribution Non-Commercial License (http://creativecommons.org/licenses/by-nc/4.0/), which permits non-commercial re-use, distribution, and reproduction in any medium, provided the original work is properly cited. For commercial re-use, please contact journals.permissions@oup.com.

J. Anim. Sci. 2018.96:1396-1404 doi: 10.1093/jas/sky048

\section{INTRODUCTION}

${ }^{1}$ Corresponding author: tlawrence@wtamu.edu

Received December 4, 2017.

Accepted March 15, 2018.
Modeling the live and carcass growth characteristics of fed cattle has been the goal of many investigations since the early part of the last century. Pioneer researchers such as Lush (1926) 
focused on the prediction of proportions of fat and bone in carcasses of cattle harvested in multiple studies and implicated the wholesale rib cut as an accurate representation of carcass composition. Later, Hopper et al. (1944) reported relationships between separable fat, lean and bone may exist among the primal rib cut, 9-10-11 rib portion and the entire carcass.

In 1946, O. G. Hankins and P. E. Howe, USDA scientists, investigated the estimation of beef carcass composition using the primal rib cut. They focused on the relationship of separable lean, fat, and bone as well as proximate analysis of protein, fat, moisture, and ash of the 9-10-11 rib dissection (RD) with those values of the carcass; strong correlations (simple $r$ values $>0.65$ ) existed among all parameters except for ash. Simple regression equations were developed that allowed for the use of the 9-10-11 RD method to estimate carcass physical and chemical composition.

Crown and Damon (1960) indicated utilization of the 12th rib cut to measure carcass yield was similar to the utilization of the 9-10-11 RD when comparing calculated $r$ values. Crouse and Dikeman (1974) re-examined methods of predicting beef carcass chemical composition; they suggested that estimated intramuscular fat content and subcutaneous fat thickness may be coupled with 9-10-11 rib dissection data to better describe variations in carcass chemical composition. Later, Nour and Thonney (1994) reported $R^{2}$ better than 0.64 for the prediction of carcass protein, moisture, and lipid. The objective of this study was to evaluate the relationship of the physical and chemical composition of 9-10-11 RD following the methods of earlier investigations to that of carcasses derived from calf-fed Holstein steers fed zilpaterol hydrochloride.

\section{MATERIALS AND METHODS}

Cattle were fed at Agri-Research Center, Inc. Feedyard (Canyon, TX). All experimental procedures followed the guidelines described in the Guide for the Care and Use of Agricultural Animals in Agricultural Research and Teaching (Federation of Animal Science Societies, Savoy, IL, 2010). Institutional animal care and use guidelines were followed according to the West Texas A\&M University cooperative research, education, and extension triangle team directive. Feeding performance, steer slaughter characteristics, grading performance, and fabrication outcomes have been previously summarized by Walter et al. (2016), May et al. (2016a), May et al. (2016b), and May et al. (2017), respectively.

\section{Separation of 9-10-11 Rib Sections}

As originally described by the early manuscript of Hankins and Howe (1946), 9-10-11 rib sections were collected from the standing rib cut based on the "Chicago" style of fabricating beef carcasses. The current industry standard for the beef rib primal is designated the Institutional Meat Purchase Specifications (IMPS, 2010) 103 rib. This primal was separated from the forequarter of each animal and contained ribs six through twelve; the IMPS 121 (beef short plate) was removed at approximately $15.2 \mathrm{~cm}$ from the most ventral portion of the longissimus dorsi. Following the Hankins and Howe (1946) procedure, the 9-10-11 rib sections were removed from the primal 103 rib using a knife immediately adjacent to the caudal edges of the 8th and 11th ribs. Once removed from the IMPS 130 primal, the 9-10-11 rib section was weighed and manually separated into the physical components of lean tissue, fat trim, and bone. Dissection of 9-10-11 rib sections (RD) allowed for the determination of separable lean (RDSL), separable fat (RDSF), separable bone (RDSB), ether extract (RDEE), protein (RDP), moisture (RDM), and ash (RDA). McEvers (2018) detailed the methods related to obtaining chemical composition of soft tissue carcass lean $(\mathbf{C L})$ and carcass fat $(\mathbf{C F})$ for determination of carcass ether extract $(\mathbf{C E E})$, protein $(\mathbf{C P})$, moisture $(\mathbf{C M})$, and ash (CA). Briefly, carcasses were separated into lean, trimmable fat, and bone. Lean and trimmable fat were coarsely ground (12.7 $\mathrm{mm}$ diameter) and then manually mixed and reground using a $3.2 \mathrm{~mm}$ fine grinding plate. Tissue samples were subsampled in triplicate for chemical analysis.

\section{Chemical Composition of 9-10-11 Rib Dissections and Carcasses}

Chemical composition of the carcass and 9-10$11 \mathrm{RD}$ was quantified after grinding and analysis of all soft tissue components. Moisture was calculated by drying samples at $105^{\circ} \mathrm{C}$ for $24 \mathrm{~h}$. Crude protein was determined using AOAC method 990.03 (2000), ether extract was determined through the AOAC official method 2003.06 (2006), with ash being calculated using AOAC official method 942.05 (1943).

\section{Statistical Analysis}

The MEANS procedure of SAS (SAS 9.3, SAS Institute, Cary, NC) was used to calculate descriptive statistics of all independent and dependent variables. The MIXED procedure was used to evaluate differences between RD and carcass physical and 
chemical characteristics by diet treatment, with the fixed effects of zilpaterol hydrochloride $(\mathrm{ZH})$ supplementation, composition type (RD vs. whole carcass), and $\mathrm{ZH} \times$ composition type interaction. The CORR procedure was used to calculate simple $r$ values amongst predictive variables and independent variables. The REG procedure was used to model dependent variables of interest (separable lean, fat, and bone) as well as chemical composition (moisture, fat, protein, and ash) of carcasses using predictive variables of physical and chemical composition of the 9-10-11 RD. In addition to selection of predictive variables that mirrored that of the original Hankins and Howe (1946) manuscript, the authors also added the nominal variable of $\mathrm{ZH}$ inclusion. This variable was used in all regression equations as a dummy variable where the user would input the number " 1 " to represent cattle that had received $\mathrm{ZH}$ for $20 \mathrm{~d}$ with the number " 0 " representing cattle that did not receive the supplement.

\section{RESULTS AND DISCUSSION}

\section{Descriptive Statistics of Sample Population}

Mean, standard deviation, and ranges for all variables used in model development are reported by diet treatment (Table 1). Data from steers utilized in the Hankins and Howe (1946) investigation had similar values for RDSL, RDEE, RDM, RDA, and CA to our sample population. However, values for RDSB, RDP, CL, CB, and CM were greater (4.9, $2.32,2.38,1.06$, and $2.96 \%$, respectively) for our population of calf-fed Holstein steers as compared to the previous investigation. Values for RDSF, CF, and CEE were less $(10.17,6.05$, and $4.42 \%$, respectively) than those reported in the earlier investigation. In comparison to the earlier-maturing British-based population utilized in the original investigation, reductions in carcass lean and fat with subsequent increases in bone would be expected of data derived from calf-fed Holstein steers.

Value ranges for RDSF from the current trial are less than previous data (Hankins and Howe, 1946) with RDSL and RDSB being greater. Rib dissection ether extract, RDP, and RDM from the current data follow similar trends to previous data, however, RDA was reported to have a larger range of values comparatively. Carcass composition data from the current trial were similar to previous data with CA having a wider range. Differences may be in part due to the growth rate differences of calf-fed Holsteins compared to native beef type steers as well as advancements in animal genetics resulting in changes in carcass composition (Bertrand et al., 1983). Other reasons for differences may include experimental design of the trial where cattle were harvested over a wide range of body weights and compositional endpoints.

\section{Comparison of Rib Dissection and Carcass Samples}

No $\mathrm{ZH} \times \mathrm{COMP}$ interactions $(P \geq 0.11)$ were calculated amongst rib dissection or carcass composition measures (Table 2). Physical and chemical differences between rib dissection and carcass samples were evaluated by dietary treatment. Values for

Table 1. Descriptive statistics of rib dissection and carcass samples by dietary treatment

\begin{tabular}{|c|c|c|c|c|c|c|c|c|}
\hline \multirow[b]{2}{*}{ Item } & \multicolumn{4}{|c|}{$\mathrm{ZH}^{1}$} & \multicolumn{4}{|c|}{$\mathrm{CON}^{2}$} \\
\hline & Mean & SD & Minimum & Maximum & Mean & SD & Minimum & Maximum \\
\hline Number of carcasses & 55 & - & - & - & 55 & - & - & - \\
\hline Rib dissection separable lean, $\%$ & 58.2 & 3.4 & 49.5 & 65.3 & 55.9 & 3.8 & 42.3 & 63.1 \\
\hline Rib dissection separable fat, $\%$ & 16.2 & 4.1 & 7.2 & 23.7 & 17.6 & 4.7 & 8.0 & 27.6 \\
\hline Rib dissection separable bone, $\%$ & 25.5 & 3.4 & 19.6 & 35.7 & 26.1 & 3.8 & 14.9 & 34.2 \\
\hline Rib dissection ether extract, $\%$ & 31.4 & 8.4 & 14.7 & 49.0 & 33.1 & 8.6 & 14.6 & 52.7 \\
\hline Rib dissection protein, $\%$ & 17.3 & 3.3 & 9.9 & 25.3 & 16.8 & 3.1 & 10.0 & 26.5 \\
\hline Rib dissection moisture, $\%$ & 50.6 & 6.1 & 40.0 & 66.2 & 49.4 & 6.6 & 35.3 & 64.6 \\
\hline Rib dissection ash, $\%$ & 0.78 & 0.3 & 0.5 & 2.7 & 0.68 & 0.1 & 0.20 & 1.03 \\
\hline Carcass separable lean, $\%$ & 60.8 & 3.6 & 52.3 & 67.7 & 59.1 & 3.5 & 53.5 & 66.3 \\
\hline Carcass separable fat, $\%$ & 19.0 & 4.8 & 10.4 & 27.6 & 19.6 & 4.4 & 11.2 & 29.3 \\
\hline Carcass separable bone, $\%$ & 17.6 & 1.9 & 14.5 & 22.1 & 18.7 & 2.3 & 12.0 & 23.11 \\
\hline Carcass ether extract, $\%$ & 24.2 & 5.2 & 14.8 & 35.2 & 25.5 & 6.0 & 14.0 & 37.5 \\
\hline Carcass protein, $\%$ & 17.7 & 3.0 & 6.7 & 21.6 & 17.3 & 2.9 & 6.4 & 23.4 \\
\hline Carcass moisture, $\%$ & 57.3 & 3.9 & 48.8 & 65.5 & 56.4 & 4.5 & 47.7 & 65.5 \\
\hline Carcass ash, $\%$ & 0.84 & 0.11 & 0.63 & 1.2 & 0.82 & 0.1 & 0.6 & 1.2 \\
\hline
\end{tabular}

'Zilpaterol Hydrochloride (Merck Animal Health, Summit, NJ)

${ }^{2}$ Control steers not receiving $\mathrm{ZH}$.

$\mathrm{SD}=$ Standard deviation 
CL were greater $(P<0.01)$ than RDSL for both $\mathrm{ZH}$ $(+2.6 \%)$ and CON $(+3.2 \%)$ fed cattle. Comparing separable fat, $\mathrm{CF}$ was greater $(P<0.01)$ than RDSF for both $\mathrm{ZH}(+2.8 \%)$ and control $(+2.0 \%)$ cattle. However, rib dissections had more $(P<0.01)$ separable bone than $\mathrm{CB}$ for both $\mathrm{ZH}(+7.9 \%)$ and control $(+7.4 \%)$ cattle. When Comparing dietary treatment effects within RD measures, cattle fed $\mathrm{ZH}$ had more $(P<0.01)$ RDSL $(2.3 \%)$ concurrent with less $(P=0.03)$ RDSB $(0.6 \%)$. Carcasses also followed a similar trend with $\mathrm{ZH}$ supplemented cattle exhibiting more $(P<0.01)$ separable lean $(1.7 \%)$ and less $(P=0.03)$ separable bone $(1.1 \%)$.

No difference $(P=0.27)$ was detected between RDP and CP of between diet treatment $(P=0.37)$ for protein. However, ether extract was greater $(P<0.01)$ in RD samples than that of the carcass regardless of diet treatment $(\mathrm{ZH}=+7.2 \%$; $\mathrm{CON}=+7.6 \%)$. Moreover, moisture was greater $(P<0.01)$ in carcasses compared to RD samples regardless of treatment $(\mathrm{ZH}=+6.7 \%$; $\mathrm{CON}=+7.0 \%$ ). Additionally, ash was greater in carcasses compared to RD samples $(\mathrm{ZH}=0.06 \%$; $\mathrm{CON}=0.14 \%)$ and was greater $(P<0.01)$ for $\mathrm{ZH}$ compared to $\mathrm{CON}$ animals. Through chemical composition comparisons, the differences between RD and carcass derived measurements are delineated.

\section{Correlation Analysis Between Rib Dissection and Carcass Samples}

Rib dissection separable lean was correlated $(P<0.05)$ with $\mathrm{CL}, \mathrm{CM}, \mathrm{CF}$, and CEE; simple $r$ values ranged from 0.41 to -0.31 , respectively (Table 3). Rib dissection separable fat was correlated $(P<0.05)$ with $\mathrm{CF}, \mathrm{CEE}, \mathrm{CA}, \mathrm{CP}, \mathrm{CB}, \mathrm{CM}$, and CL; simple $r$ values ranged from 0.71 to -0.32 , respectively. Rib dissection separable bone was correlated $(P<0.05)$ with $\mathrm{CB}, \mathrm{CL}, \mathrm{CP}, \mathrm{CA}, \mathrm{CM}$, $\mathrm{CEE}$, and $\mathrm{CF}$; simple $r$ values ranged from -0.53 to 0.24 . Rib dissection ether extract was correlated $(P<0.05)$ with $\mathrm{CF}, \mathrm{CEE}, \mathrm{CA}, \mathrm{CP}, \mathrm{CB}, \mathrm{CM}$, and $\mathrm{CL} ; r$ values ranged from 0.83 to -0.36 . Of note, RDEE had the strongest relationship $(r=0.83)$ of all RD variables with carcass composition. Rib dissection protein was correlated $(P<0.05)$ with $\mathrm{CL}$, $\mathrm{CM}, \mathrm{CB}, \mathrm{CP}, \mathrm{CA}, \mathrm{CEE}$, and $\mathrm{CF}$; simple $r$ values ranged from -0.57 to 0.26 . Rib dissection moisture was correlated $(P<0.05)$ with $\mathrm{CL}, \mathrm{CM}, \mathrm{CB}, \mathrm{CP}$, $\mathrm{CA}, \mathrm{CEE}$, and $\mathrm{CF}$; simple $r$ values ranged from -0.80 to 0.33 . Rib dissection ash was correlated $(P<0.05)$ with CL, CA, CM, CB, CP, CEE, and $\mathrm{CF} ; r$ values ranged from 0.42 to 0.22 .
Compared to the original work from Hankins and Howe (1946), the correlations of rib dissection values to carcass values were lower than observed in the original data. The simple $r$ values of 9-10-11 separable lean, fat, and bone with that of the carcass in the original manuscript ranged from 0.80 to 0.93 , which were greater than the simple $r$ values reported in this investigation. Similarly, Crown and Damon (1960) reported simple $r$ values ranging from 0.94 to 0.73 for the relationships of 9-10-11 separable lean, fat, and bone with carcass separable lean, fat and bone. Compared to the results of the current investigation, the simple $r$ values are significant yet not as powerful as those reported in earlier studies. This may be due to the composition of gain of Holstein steers differing from that of native beef-type cattle due to selection pressure for increased milk yield. This selection pressure has led to increased frame size and associated delayed maturation (Bertrand et al., 1983).

Focusing on simple $r$ values reported in the original manuscript (Hankins and Howe, 1946) among 9-10-11 moisture, protein, fat, and ash, with carcass chemical composition, values reported were 0.92 , $0.83,0.91$, and 0.51 , respectively. In the current trial, simple $r$ values were considerably weaker with values being $0.66,0.31,0.75$, and 0.37 for the relationships of RDM, RDP, RDEE, and RDA with CM, $\mathrm{CP}, \mathrm{CEE}$, and CA, respectively. These differences are likely due to the differences in physical composition of calf-fed Holstein steer carcasses relative to the population of British breed cattle investigated in the 1940's.

\section{Prediction of Carcass Composition}

Using the physical and chemical composition of 9-10-11 rib sections coupled with the effect of $\mathrm{ZH}$ supplementation, several models were developed to predict carcass composition (Table 4). For prediction of $\mathrm{CF}$ an equation with an $R^{2}$ of 0.50 and root mean square error (RMSE) of $0.03[\mathrm{CF}=0.066+$ $(0.737 \times \mathrm{RDSF})+(0.004 \times \mathrm{ZH}$ (dummy variable where $0 \mathrm{~d}=0 ; 20 \mathrm{~d}=1)$ )] was developed. Prediction of $\mathrm{CL}$ was estimated using an equation with an $R^{2}$ of 0.16 and $\mathrm{RMSE}$ of 0.03 [CL $=0.393+(0.354 \times$ $\mathrm{RDSL})+(0.009 \times \mathrm{ZH})]$. Prediction of $\mathrm{CB}$ was estimated using an equation with an $R^{2}$ of 0.28 and RMSE of $0.02[\mathrm{CB}=0.111+(0.292 \times \mathrm{RDSB})-$ $(0.009 \times \mathrm{ZH})]$. With the current equations developed having $R^{2}$ values $\leq 0.50$, the ability of the 9-10-11 RD to explain carcass physical composition may be less than ideal for calf-fed Holstein steers. 
The intercept of the current equation developed for the prediction of CL is greater, concurrent with a reduced slope compared to that of the equation included in the Hankins and Howe (1946) study. For $\mathrm{CF}$, the current investigation has a similar slope; however, the intercept is greater than the prior study. Carcass bone also differed from the earlier investigation with an increased intercept and less slope. These differences may further explain the lack of prediction associated with using 9-10-11 $\mathrm{RD}$ analysis to estimate carcass tissue components of calf-fed Holstein steers.

For prediction of carcass chemical composition, equations were developed for all components. For prediction of CM, an equation was developed with an adjusted $R^{2}$ of 0.43 and an RMSE of 0.03 $[\mathrm{CM}=0.349+(0.435 \times \mathrm{RDM})+(0.004 \times \mathrm{ZH})]$. Prediction of CEE included an equation with an $R^{2}$ of 0.56 and RMSE of $0.04[\mathrm{CEE}=0.089+(0.5 \times$ $\mathrm{RDEE})-(0.004 \times \mathrm{ZH})]$. Carcass protein was predicted with an equation having an $R^{2}$ of 0.08 and RMSE of $0.003[\mathrm{CP}=0.126+(0.283 \times \mathrm{RDP})+$ $(0.002 \times \mathrm{ZH})$ ]. For prediction of $\mathrm{CA}$ an equation with an adjusted $R^{2}$ of 0.12 and RMSE of 0.001 $[\mathrm{CA}=0.007+(0.174 \times \mathrm{RDA})+(0.00003 \times \mathrm{ZH})]$ was developed.

Compared to the Hankins and Howe (1946) investigation, the current equation developed for $\mathrm{CM}$ had a greater intercept concurrent with less slope. Moreover, compared to the equation developed by Nour and Thonney (1994), the current equation exhibited a greater intercept and with less slope. Furthermore, CEE differed compared to the Hankins and Howe (1946) method with the intercept being greater with less slope. When CEE was compared to the equation developed by Nour and Thonney (1994), the current equation exhibited a greater intercept and with less slope. For prediction of $\mathrm{CP}$, the intercept and slope of the Hankins and Howe (1946) method was less compared to the current equation. However, when compared to Nour and Thonney (1994), the current equation possessed a greater slope with less slope. Compared to data reported by Crouse and Dikeman (1974), prediction equations for $\mathrm{CM}, \mathrm{CEE}$, and $\mathrm{CP}$ all had $R^{2}$ values greater than 0.77 . For prediction of $\mathrm{CM}$, the $R^{2}$, intercept, and slope of the current investigation were lesser. Additionally, for prediction of CEE, prior data had an increased $R^{2}$, intercept, and slope. Compared to the current equation for prediction of $\mathrm{CP}$, the previous investigation had a reduced intercept and an increased slope. Although the sample size of the current trial was similar to that of the Hankins and Howe (1946) investigation and greater than the investigation of Crouse and Dikeman (1974), the newly developed equations are unable to account for the variation introduced by the Holstein steers. The inability to accurately account for variation in the current trial may suggest the 9-10-11 rib section is not an appropriate representation of the entire calf-fed Holstein carcass.

To illustrate the predictive ability of the models developed in this investigation, two figures were constructed. Figure 1 exhibits the ability of the current model derived from the fabrication of the 9-10-11 RDSL to estimate CL. The figure was constructed by using the model estimates for each carcass with
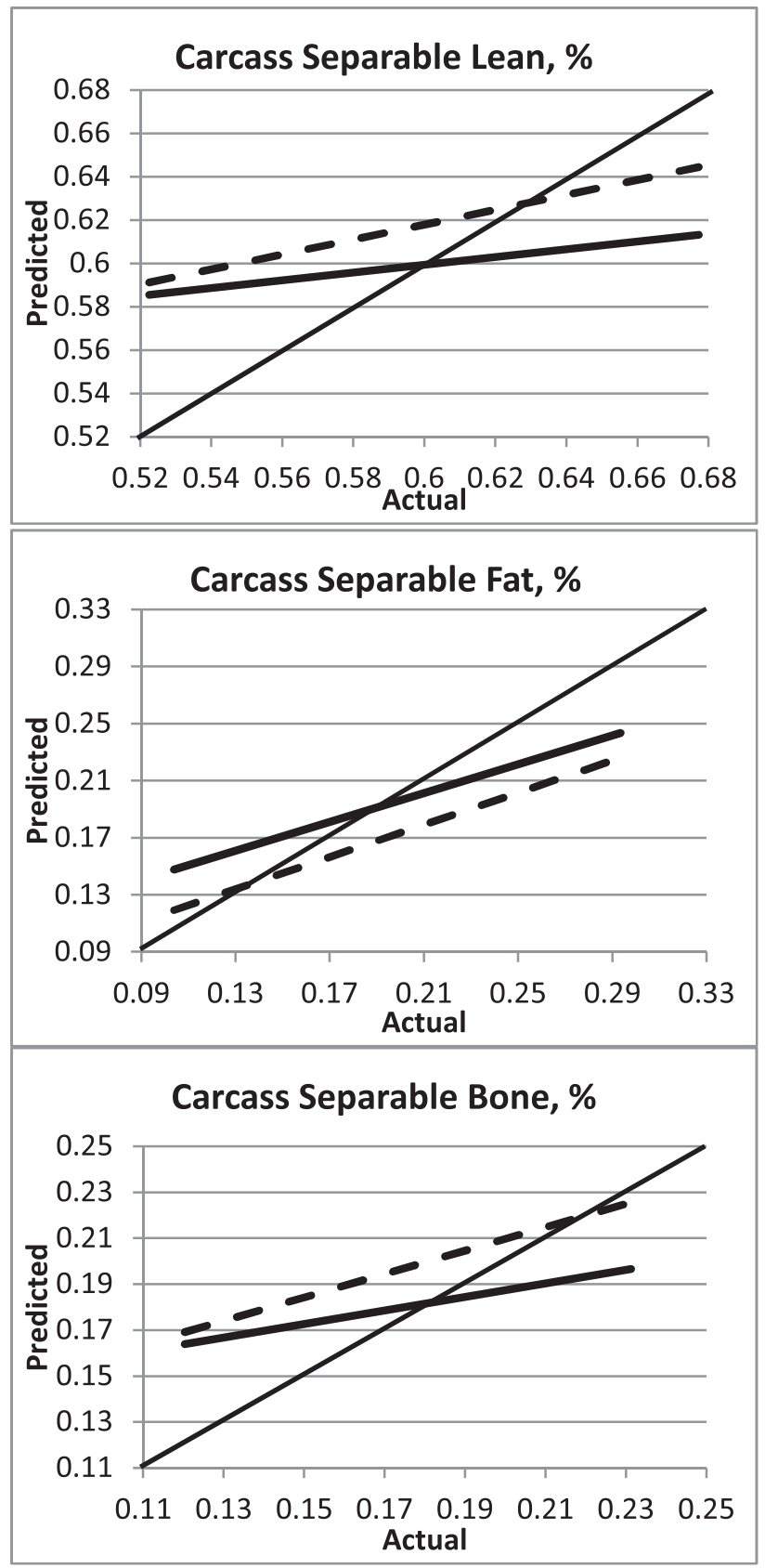

Figure 1. Actual and predicted carcass separable lean, fat, and bone of calf-fed Holstein steers $(n=115$; solid line) and the original model (dashed line) developed by Hankins and Howe (1946). 
the ordered pair $(\mathrm{x}, \mathrm{y})$ being the actual ( $\mathrm{x}$ variable) and predictive values (y variable) to indicate goodness of fit. For comparisons, equations developed by Hankins and Howe (1946) were included. Figure 1 describes the current model and the classical model's ability to explain CL. Both models are unable to predict CL when using a goodness of fit line as a reference. Although the best fit lines never intercept amongst the two equations, the classic model may have a slight advantage compared to the current model. Comparing the figures constructed for physical carcass components, the model developed for $\mathrm{CF}$ accounts for more variation compared to those developed for $\mathrm{CL}$ and $\mathrm{CB}$ with increased data points following a linear trend. Moreover, the prediction of $\mathrm{CB}$ was overestimated by the classic model with the new model having more data points falling along the goodness of fit line.

Describing the developed models ability to explain variation in proximate analysis, Fig. 2 exhibits the ability to account for CEE, CP, CM, and CA. The best fit model for prediction of chemical composition was for CEE with more data points falling along the best fit line with the worst model being that for the prediction of CA. Additionally, the model developed by Hankins in Howe (1946) overestimated CEE compared to the newly developed model. Both the new model and earlier model lack the ability to account for variation in CP. For prediction of CM, the Hankins and Howe (1946) equation underestimates moisture compared to the newly calculated model. The new model developed for ash lacks the ability to account for variation with the trend line of the equation being almost perpendicular to the goodness of fit line.

For comparison of $\mathrm{RD}$ and carcass physical composition, Fig. 3 was developed. Values for CL were greater than that of the $\mathrm{RD}$ derived from the same carcasses. Additionally, CF is slightly greater than that of the RD with most data points exceeding the one to one line placed in the figure. Comparing separable bone, RDB was greater for all carcasses with two exceptions compared to CB. These figures illustrate the inability of the 9-10-11 rib dissections to accurately account for variation in physical carcass composition. Potential reasons for difference between the various physical components of the carcass and RD may be due to a difference in genetic propensity for the development of subcutaneous fat coupled to increased proportionality of bone in calf-fed Holsteins compared to native beef-type cattle.

Comparing chemical composition, Fig. 4 indicates differences amongst RD and carcass derived
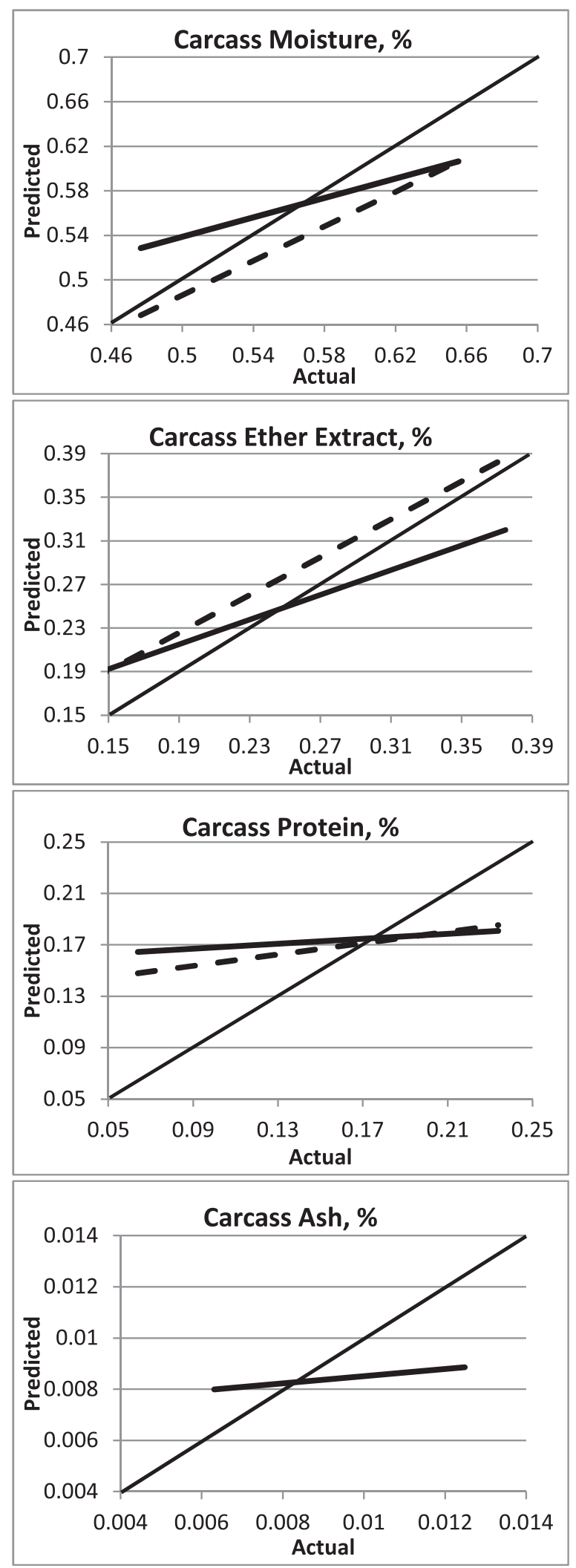

Figure 2. Actual and predicted carcass moisture, either extract, protein, and ash of calf-fed Holstein $(n=115$; solid line) and the original model (dashed line) developed by Hankins and Howe (1946).

ether extract, protein, moisture, and ash. Rib dissections yielded more ether extract than carcass soft tissue for most carcasses. Furthermore, carcasses had more protein relative to protein of the 


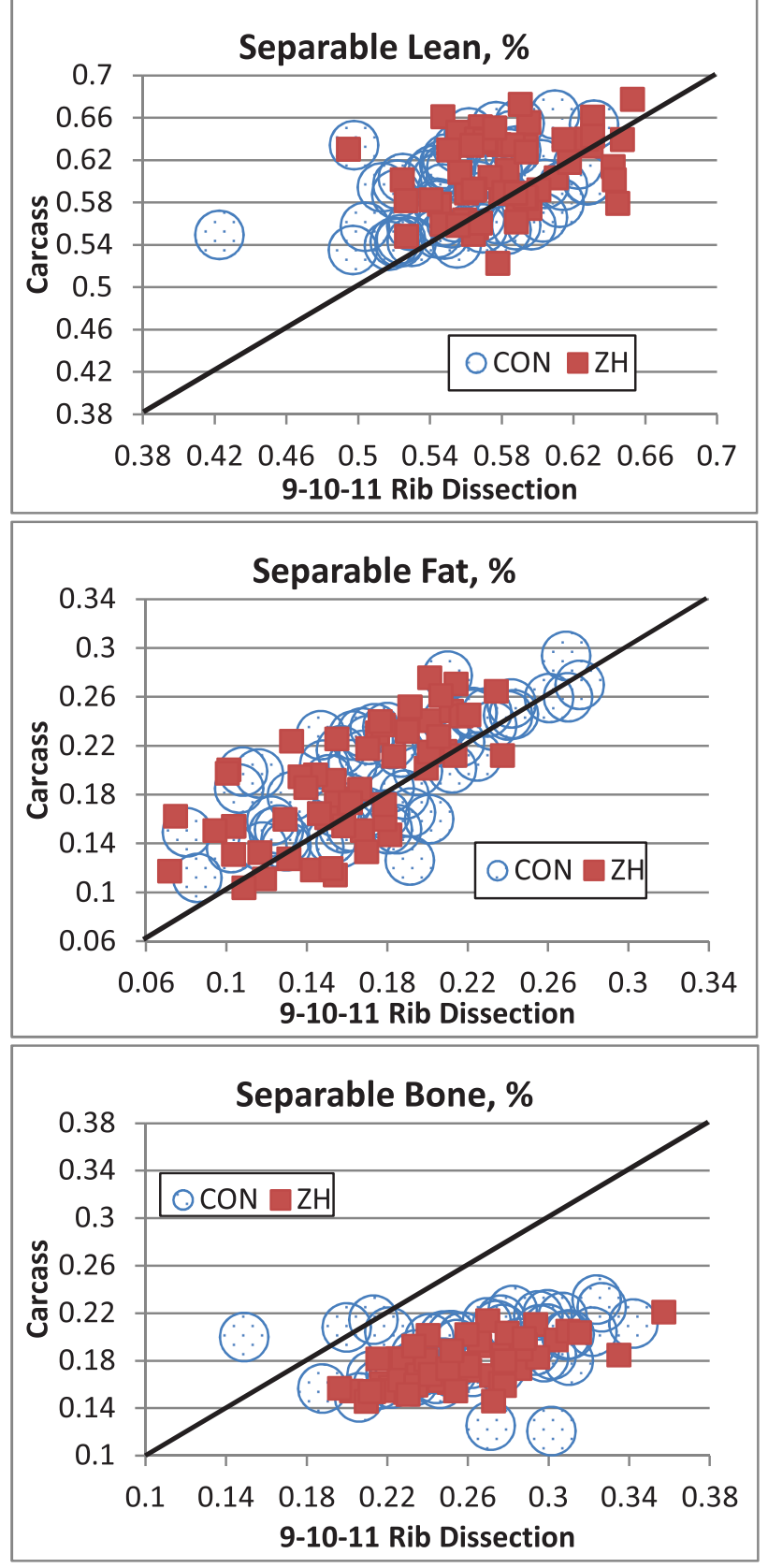

Figure 3. Association between carcass and 9-10-11 rib dissection separable lean, bone, and fat.

RD. Carcass moisture was greater than RDM for most carcasses regardless of diet treatment. Ash was relatively consistent for most carcasses when comparing CA and RDA with a slight increase in CA over RDA. The RD may not accurately represent the carcass due to shifts in lipid deposition from the rib to the carcass. The decrease in lipid deposition subcutaneously likely affects the ability of the RD to serve as a representative sample for prediction of calf-fed Holstein carcass composition.

In summary, the use of the 9-10-11 RD may not be suitable for the prediction of carcass physical and chemical composition of calf-fed Holstein steers. Differences in chemical and physical composition
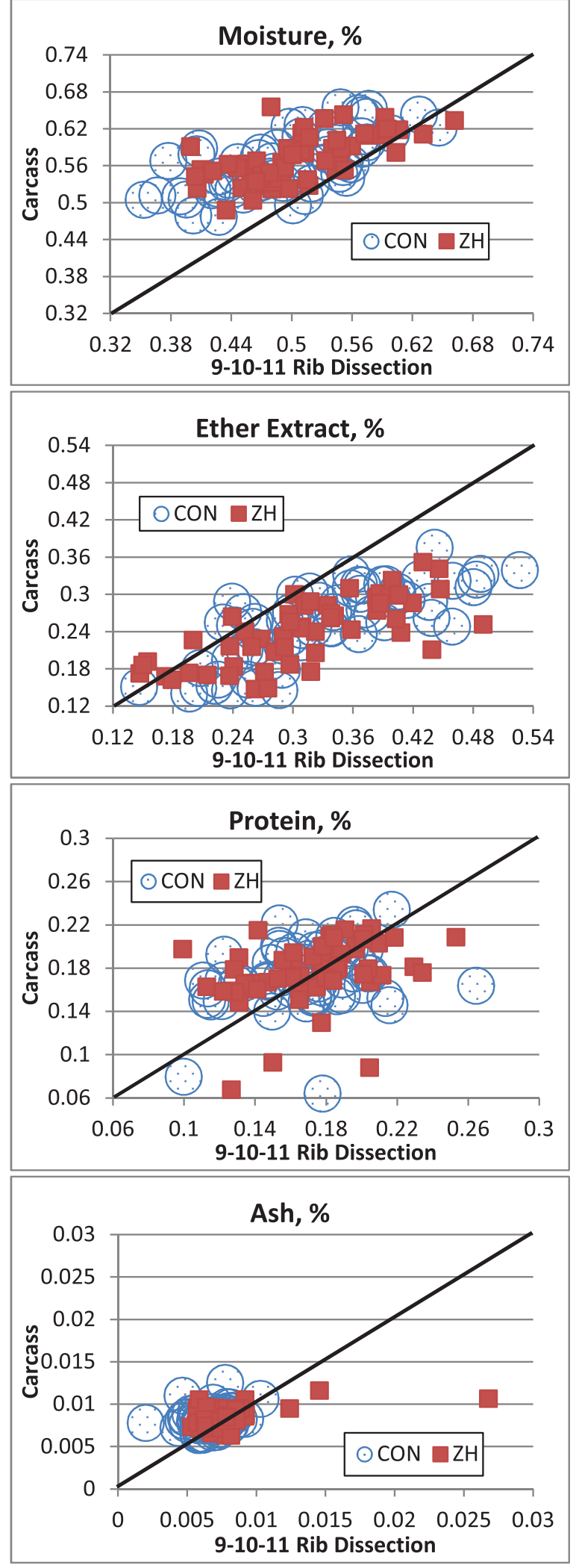

Figure 4. Association between carcass and 9-10-11 rib dissection moisture, either extract, protein, and ash.

of 9-10-11 RD compared to that of the carcass illustrate why utilization of this sample may result in erroneous estimates for this particular population. Furthermore, the inability of newly developed and 
Table 2. Comparison of least squares means between rib dissection and carcass separation within diet treatment

\begin{tabular}{|c|c|c|c|c|c|c|c|c|}
\hline \multirow[t]{2}{*}{ Item } & \multicolumn{2}{|c|}{$\mathrm{ZH}^{1}$} & \multicolumn{2}{|c|}{$\mathrm{CON}^{2}$} & \multirow{2}{*}{$\frac{\text { SEM }}{-}$} & \multirow{2}{*}{$\frac{\mathrm{ZH}^{1}}{-}$} & \multirow{2}{*}{$\frac{\mathrm{COMP}^{3}}{-}$} & \multirow{2}{*}{$\frac{\mathrm{ZH}^{1} \times \mathrm{COMP}^{3}}{-}$} \\
\hline & Rib dissection & Carcass & Rib dissection & Carcass & & & & \\
\hline Cattle & 55 & 55 & 55 & 55 & - & - & - & - \\
\hline Separable Lean, \% & 58.2 & 60.8 & 55.9 & 59.1 & 0.5 & $<0.01$ & $<0.01$ & 0.54 \\
\hline Separable Fat, \% & 16.2 & 19.0 & 17.6 & 19.6 & 0.6 & 0.08 & $<0.01$ & 0.49 \\
\hline Separable Bone, $\%$ & 25.5 & 17.6 & 26.1 & 18.7 & 0.4 & 0.03 & $<0.01$ & 0.56 \\
\hline Ether Extract, \% & 31.4 & 24.2 & 33.1 & 25.5 & 0.9 & 0.12 & $<0.01$ & 0.81 \\
\hline Protein, $\%$ & 17.3 & 17.7 & 16.8 & 17.3 & 0.4 & 0.37 & 0.27 & 0.90 \\
\hline Moisture, $\%$ & 50.6 & 57.3 & 49.4 & 56.4 & 0.7 & 0.14 & $<0.01$ & 0.84 \\
\hline Ash, $\%$ & 0.78 & 0.84 & 0.68 & 0.82 & 0.02 & 0.01 & $<0.01$ & 0.11 \\
\hline
\end{tabular}

'Zilpaterol Hydrochloride (Merck Animal Health, Summit, NJ)

${ }^{2}$ Control steers not receiving ZH.

${ }^{3}$ Composition of RD and Carcasses

Table 3. Correlations between rib dissection and carcass separation samples

\begin{tabular}{|c|c|c|c|c|c|c|c|}
\hline \multirow[b]{2}{*}{ Carcass } & \multicolumn{7}{|c|}{ Rib dissection } \\
\hline & Separable lean, $\%$ & Separable fat, $\%$ & Separable bone, $\%$ & Ether extract, $\%$ & Protein, $\%$ & Moisture, $\%$ & Ash, $\%$ \\
\hline Separable lean, $\%$ & $0.41 * * *$ & $-0.68 * * *$ & $0.39 * * *$ & $-0.76 * * *$ & $0.55^{* * *}$ & $0.72 * * *$ & $0.42^{* * *}$ \\
\hline Separable fat, $\%$ & $-0.31 * *$ & $0.71 * * *$ & $-0.53 * * *$ & $0.83^{* * *}$ & $-0.57 * * *$ & $-0.80 * * *$ & $-0.42 * * *$ \\
\hline Separable bone, $\%$ & 0.02 & $-0.44 * * *$ & $0.50 * * *$ & $-0.60 * * *$ & $0.41 * * *$ & $0.58 * * *$ & $0.29 * *$ \\
\hline Ether extract, $\%$ & $-0.31 * *$ & $0.58 * * *$ & $-0.34 * *$ & $0.75 * * *$ & $-0.50 * * *$ & $-0.74 * * *$ & $-0.39 * * *$ \\
\hline Protein, $\%$ & 0.13 & $-0.35^{* *}$ & $0.30 * *$ & $-0.46^{* * *}$ & $0.31 * *$ & $0.45^{* * *}$ & $0.22 *$ \\
\hline Moisture, \% & $0.32 * *$ & $-0.52 * * *$ & $0.24 * *$ & $-0.67 * * *$ & $0.45^{* * *}$ & $0.66^{* * *}$ & $0.36 * * *$ \\
\hline Ash, $\%$ & 0.18 & $-0.32 * *$ & $0.25 * *$ & $-0.36 * * *$ & $0.26^{* *}$ & $0.33^{* *}$ & $0.37 * * *$ \\
\hline
\end{tabular}

$*, * *$, and $* * *$ indicates significance at the $0.05,0.01$, and 0.0001 level, respectively.

Table 4. Prediction equations for the determination of carcass composition of Holstein steers from rib dissection measures and $\mathrm{ZH}$ inclusion status

\begin{tabular}{lccccc}
\hline \hline Item & $n$ & Adjusted R & $P$ value & Root MSE & Equation \\
\hline Carcass Separable Lean, $\%$ & 115 & 0.16 & $<0.0001$ & 0.03 & $=0.393+\left(0.354 \times \mathrm{RDSL}^{1}\right)+\left(0.009 \times \mathrm{ZH}^{2}\right)$ \\
Carcass Separable Fat, $\%$ & 115 & 0.50 & $<0.0001$ & 0.03 & $=0.066+\left(0.737 \times \mathrm{RDSF}^{3}\right)+\left(0.004 \times \mathrm{ZH}^{2}\right)$ \\
Carcass Separable Bone, $\%$ & 115 & 0.28 & $<0.0001$ & 0.02 & $=0.111+\left(0.292 \times \mathrm{RDSB}^{4}\right)-\left(0.009 \times \mathrm{ZH}^{2}\right)$ \\
Carcass Ether Extract, $\%$ & 115 & 0.56 & $<0.0001$ & 0.04 & $=0.089+\left(0.5 \times \mathrm{RDEE}^{5}\right)-\left(0.004 \times \mathrm{ZH}^{2}\right)$ \\
Carcass Protein, $\%$ & 115 & 0.08 & 0.0034 & 0.03 & $=0.126+\left(0.283 \times \mathrm{RDP}^{6}\right)+\left(0.002 \times \mathrm{ZH}^{2}\right)$ \\
Carcass Moisture, $\%$ & 115 & 0.43 & $<0.0001$ & 0.03 & $=0.349+\left(0.435 \times \mathrm{RDM}^{7}\right)+\left(0.004 \times \mathrm{ZH}^{2}\right)$ \\
Carcass Ash, $\%$ & 115 & 0.12 & 0.0002 & 0.001 & $=0.007+\left(0.174 \times \mathrm{RDA}^{8}\right)+\left(0.00003 \times \mathrm{ZH}^{2}\right)$
\end{tabular}

${ }^{1}$ Rib dissection separable lean, \% of 9-10-11 sample weight.

${ }^{2}$ Zilpaterol Hydrochloride, Merck Animal Health, Summit, NJ (0=No Supplement, 1=Supplemented ZH for $\left.20 \mathrm{~d}\right)$.

${ }^{3}$ Rib dissection separable fat, $\%$ of 9-10-11 sample weight.

${ }^{4} \mathrm{Rib}$ dissection separable bone, $\%$ of 9-10-11 sample weight.

${ }^{5} \mathrm{Rib}$ dissection ether extract, \% of soft tissue sample.

${ }^{6}$ Rib dissection protein, $\%$ of soft tissue sample.

${ }^{7}$ Rib dissection moisture, $\%$ of soft tissue sample.

${ }^{8}$ Rib dissection ash, $\%$ of soft tissue sample. 
classical equations to account for all components supports the findings of this investigation. More data related to calf-fed Holsteins is warranted in an effort to discover readily obtainable methods to predict carcass composition.

Conflict of interest statement. None declared.

\section{LITERATURE CITED}

Bertrand, J. K., R. L. Willham, and P. J. Berger. 1983. Beef, dairy, and beef x dairy carcass characteristics. J. Anim. Sci. 57:1440-1448. doi:10.2527/jas1983.5761440x

Crouse, J. D. and M. E. Dikeman. 1974. Methods of estimating beef carcass chemical composition. J. Anim. Sci. 38:1190 1196. doi:10.2527/jas1974.3861190x

Crown, R. M. and R. A. Damon, Jr. 1960. The value of the 12th rib cut for measuring beef carcass yields and meat quality. J. Anim. Sci. 19:109-113. doi:10.2527/jas1960.191109x

FASS. 2010. Guide for the Care and Use of Agricultural Animals in Agricultural Research and Teaching. Savoy, IL, 2010.

Hankins, O. G. and P. E. Howe. 1946. Estimation of the composition of beef carcasses and cuts. United States Department of Agriculture Technical Bulletin No. 926. U.S. Government Printing Office. Washington, D.C.

Hopper, T. H. 1944. Methods of estimating the physical and chemical composition of cattle. J. Agr. Res. 68: 239-268.

IMPS. 2010. Institutional Meat Purchase Specifications. Fresh Beef-Series 100. www.ams.usda.gov/AMSv1.0/getfile?DocName $=$ STELDEV3003281 (Accessed May 21, 2014).
Lush, J. L. 1926. Practical methods of estimating proportions of fat and bone in cattle slaughtered in commercial packing plants. J. Agr. Res. 32:727-755.

May, N. D., T. J. McEvers, L. J. Walter, J. A. Reed, J. P. Hutcheson, and T. E. Lawrence. 2016a. Byproduct yields of serially harvested calf-fed Holstein steers fed zilpaterol hydrochloride. J. Anim. Sci. 94:4006-4015. doi:10.2527/jas.2016-0486

May, N. D., T. J. McEvers, L. J. Walter, J. A. Reed, J. P. Hutcheson, and T. E. Lawrence. 2016b. Carcass grading characteristics of serially harvested calf-fed holstein steers fed zilpaterol hydrochloride. j. Anim. Sci. 94:5129-5136. doi:10.2527/jas.2016-0837

May, N. D., T. J. McEvers, L. J. Walter, J. A. Reed, J. P. Hutcheson, and T. E. Lawrence. 2017. Fabrication yields of serially harvested calf-fed holstein steers fed zilpaterol hydrochloride. j. Anim. Sci. 95:1209-1218. doi:10.2527/ jas. 2016.1246

McEvers, T. J., N. D. May, L. J. Walter, J. A. Reed, J. P. Hutcheson, and T. E. Lawrence. 2018. Empty body composition, retained energy, and carcass transfer of serially-harvested calf-fed Holstein steers supplemented zilpaterol hydrochloride. J. Anim. Sci.

Nour, A. Y. M., and M. L. Thonney. 1994. Technical note: chemical composition of Angus and Holstein carcasses predicted from rib section composition. J. Anim. Sci. 72:1239-1241. doi:10.2527/1994.7251239x

Walter, L. J., T. J. McEvers, N. D. May, J. A. Reed, J. P. Hutcheson, and T. E. Lawrence. 2016. The effect of days on feed and zilpaterol hydrochloride supplementation on feeding behavior and live growth performance of Holstein steers. J. Anim. Sci. 94: 2139-2150. doi:10.2527/ jas.2015-0012 